\title{
ON THE WEIGHTED PSEUDO ALMOST PERIODIC SOLUTIONS FOR LIÉNARD - TYPE SYSTEMS WITH VARIABLE DELAYS
}

RAMAZAN YAZGAN, Science of Faculty, Van Yüzüncü Yil Universty, Turkey, ryazgan503@gmail.com

(iD) https://orcid.org/0000-0003-1569-8715)

\begin{abstract}
This study deals with Liénard-type differential equation systems with time-varying delays. Some sufficient conditions have been obtained for the existence and uniqueness of the weighted pseudo almost periodic solutions of the considered system by using some differential inequalities, the main features of the weighted pseudo almost periodic and Banach Fixed Point Theorem. Since the weighted pseudo almost periodic functions space is more general than the almost and pseudo almost pseudo periodic functions space, this work is a new and complementary. In addition, an example is given to show the correctness of the created conditions.

Keywords: Liénard System, Fixed Point Theorem, Almost Periodic Solution

\section{DEĞİŞKEN GECIKMELERE SAHİP LİÉNARD TİP SİSTEMLER İÇİN AĞIRLIKLI SÖZDE HEMEN HEMEN PERIYYDİK ÇÖZÜMLER ÜZERİNE}

\section{Özet}

Bu çalışma, zamanla değişken gecikmelere sahip Liénard tipi sistemler ile ilgilidir. Bazı diferansiyel eşitsizlikler, ağırlıklı sözde hemen hemen periyodik fonksiyonların temel özellikleri ve bilinen Banach sabit nokta teoreminin kullanilmasıla düşünülen modelin çözümlerinin varliğı ve tekliği için bazı yeterli şartlar elde edildi. Ağırlıklı sözde hemen hemen periyodik fonksiyonlar uzayl, hemen hemen ve sözde hemen hemen periyodik fonksiyonlar uzayından daha genel bir uzay olduğundan, bu çalışma yeni ve tamamlayıcı bir niteliktedir. Ayrıca, oluşturulan şartların doğruluğunu gösteren bir örnek verildi.

Anahtar Kelimeler: Lienard system, Sabit Nokta Teoremi, Hemen Hemen Periyodik Çözüm

Cite

Yazgan, R., (2020). “On The Weighted Pseudo Almost Periodic Solutions For Liénard -Type Systems With Variable Delays”, Mugla Journal of Science and Technology, 6(2), 89-93.

\section{Introduction}

It is known that Liénard type systems have wide applications in many fields such as engineering, physics and mechanics $[3,4,5,6,7]$. Therefore, it is very important to have information about the qualitative behavior of solutions of that type systems. When we look at the literature, we can come across many studies on qualitative behaviors of solutions such as periodicity, oscillation, almost periodicity and pseudo almost periodicity [3-8]. Gao and Liu [3] investigated the almost periodic solutions of the following Liénard type equation with time-varying delays:

$$
\begin{aligned}
x^{\prime \prime}(t) & +g(x(t)) x^{\prime}(t)+h_{0}(x(t)) \\
+ & \sum_{i=1}^{n} h_{i}(x(t-\sigma(t)))=p(t) .
\end{aligned}
$$

By applying some analysis techniques and constructing a suitable Lyapunov function, they establish some sufficient conditions which guarantee the existence and exponential stability of the almost periodic solutions for system (1.1). Liu [13] obtained some conditions by applying mathematical analysis techniques for the existence and exponential stability of the almost periodic solutions of a class of Li'enard-type systems. Xu and Liao [4] discussed following Liénard type system

$$
\begin{aligned}
& x^{\prime}(t)=-a(t) x(t)+y(t)+\phi_{1}(t), \\
& y^{\prime}(t)=-a(t) y(t)-a^{2}(t) x(t)-g(x(t)) \\
& \times\left[y(t)-a(t) x+\phi_{1}(t)\right] \\
& -h_{0}(x(t))-\sum_{i=1}^{n} h_{i}\left(x\left(t-\sigma_{i}(t)\right)\right)+\phi_{2}(t),
\end{aligned}
$$


where these authors got some conclusions about the pseudo almost periodic solutions of system (1.2).

To the best of information from literature, there is no study related to the weighted pseudo almost periodic solutions of the equation (1.2). Our purpose in this study is to obtain some sufficient conditions for the existence and uniqueness of weighted pseudo almost periodic solutions of system (1.2). The results obtained here are new and complementary previous studies.

\section{Preliminary Results}

Define the following notations:

$$
\begin{aligned}
& \left\{x_{i}(t)\right\}=\left(x_{1}(t), x_{2}(t)\right) \in R^{2}, \quad|x|=\left\{\left|x_{i}(t)\right|\right\} \quad \text { and } \\
& \|x(t)\|=\max _{1 \leq i \leq 2}\left\{\left|x_{i}(t)\right|\right\} . \text { Let } B C(R, R) \text { denote collection of }
\end{aligned}
$$
bounded continuous functions. $B C(R, R)$ is Banach space with norm $\|\theta\|_{\infty}=\sup _{t \in R}|\theta(t)|$ Also we use the notations

$$
\theta^{+}=\sup _{t \in R}|\theta(t)|, \quad \theta^{-}=\inf _{t \in R}|\theta(t)|,
$$

where $\theta(t) \in B C(R, R)$.

Definition 2.1 [1] A function $f$ is almost periodic if every sequence $\left\{f\left(t+T_{n}\right)\right\}$ of translations of $f$ has a subsequence that converges uniformly for $t \in R$.

Definition 2.2 [9] If there is a continuous function $f: R \rightarrow X$ such that $f=f_{1}+f_{2}$, this function is called pseudo almost periodic function. Where $f_{1} \in A P(X)$ and $f_{2} \in P A P_{0}(X)$.

$P A P_{0}$ is defined by

$P A P_{0}(R, R):=\left\{f_{2} \in B C(R, R) \mid \quad \lim _{r \rightarrow \infty} \frac{1}{2 r} \int_{-r}^{r}\left\|f_{2}(t)\right\| d t=0\right\}$.

Let $\Lambda$ denote the set of functions (weight) for any $t \in R, v(t) \in R$, is positive locally integrable function. If $v \in \Lambda, r>0$, let set $Q:=[-r, r]$ such that

$$
\mu\left(Q_{r}\right):=\int_{Q_{r}} v(x) d x .
$$

The space of weights $\Lambda_{\infty}$ is defined by

$$
\Lambda_{\infty}:=\left\{v \in \Lambda: \inf _{x \in R} v(x)=v_{0}>0 \text { and } \lim _{r \rightarrow \infty} v\left(Q_{r}\right)=\infty\right\} .
$$

Definition 2.3 [9] Fix $v \in \Lambda_{\infty}$. If there is a continuous function $f: R \rightarrow X$ such that $f=f_{1}+f_{2}$, this function is called pseudo almost periodic function, where $f_{1} \in A P(X)$ and $f_{2} \in P A P_{0}(X)$.

$$
\begin{aligned}
& P A P_{0}(R, v)= \\
& \left\{f_{2} \in B C(R, R): \lim _{r \rightarrow \infty} \frac{1}{v([-r, r])} \int_{-r}^{r}\left\|f_{2}(t)\right\| v(\mathrm{t}) d t=0\right\} .
\end{aligned}
$$

Lemma 2.1 [8] Fix $v \in \Lambda_{\infty}$. Assume that for any $s \in R$,

$$
\varlimsup_{|t| \rightarrow \infty} \frac{v(s+t)}{v(t)}<\infty
$$

Then $P A P(X, v)$ is translation invariant

In view of proposition Lemma 2.1, we give the translation invariant class of weighted pseudo almost periodic functions as follows:

$$
\Lambda_{\infty}^{\operatorname{Inv}}:=\left\{v \in \Lambda_{\infty}: \varlimsup_{|t| \rightarrow \infty} \frac{v(t+s)}{v(t)} \text { is finite, for all } s \in R\right\} .
$$

In the light of that information a fixed $v \in \Lambda_{\infty}^{\mathrm{Inv}}$, it is clear that $P A P(X, v)$ is Banach space.

Lemma 2.2 [12] Let $v \in \Lambda_{\infty}$. If $f(t) \in P A P(R, v)$, $\varpi(t) \in C^{1}(R, R), \varpi(t)$ nonnegative, $\varpi^{\prime}(t) \leq 1$, then $f(t-\varpi(t)) \in P A P(R, v)$.

The following conditions are given for our main results:

$\left.\mathrm{N}_{1}\right) H_{i}, g$ are global Lipschitz with Lipschitz constants, $L_{i}^{h}, L_{g}$ respectively and there exists positive $\xi$ such that

$\left|H_{i}\left(x_{1}\right)-H_{i}\left(x_{2}\right)\right| \leq L_{i}^{h}\left|x_{1}-x_{2}\right|$ for all $x_{1}, x_{2} \in R,|g(x)| \leq \xi$, $H_{i}(0)=0$.

$\left.\mathrm{N}_{2}\right) \sigma_{0}(t), \sigma_{i}(t), a(t), \phi_{1}(t), \phi_{2}(t), \quad p(t) \in P A P(R, R, v)$, $a(t)>0$, for all $t \in R, i=1,2, \ldots, n$.

$v: R \rightarrow(0, \infty)$ is continuous and

$$
\sup _{t \in R}\left[\frac{v(t+s)}{v(t)}\right]<\infty, \quad \sup _{t \in R}\left[\frac{\mu(T+r, v)}{\mu(T, v)}\right]<\infty .
$$

$\mathrm{N}_{3}$ ) i) $\chi=\left(a^{-}\right)^{-1} \max \left\{\sup _{t \in R}\left|\phi_{1}(\mathrm{t})\right|, \sup _{t \in R}\left|\phi_{2}(\mathrm{t})\right|\right\}$

ii)

$v=\left(a^{-}\right)^{-1} \max \left\{1, \sup _{t \in R}\left[a^{2}(t)+\xi\left[1+a(t)+\phi_{1}(t)+\sum_{i=1}^{n} H_{i}\right]\right\}\right.$, 
iii)

$$
\pi=\left(a^{-}\right)^{-1} \max \left(\sup _{t \in R}\left[a^{2}(t)+\xi\left[2+a(t)+\phi_{1}(t)+\sum_{i=0}^{n} H_{i}\right]\right)\right. \text {. }
$$

$\mathrm{N}_{4}$ )

$$
\sup _{T>0}\left\{\int_{-T}^{T} e^{-a^{-}(T+t)} v(t) d t\right\}<\infty
$$

\section{Existence and uniqueness of wpap}

Theorem 3.1 Suppose that $\left(N_{1}\right)-\left(N_{4}\right)$ hold. Define a nonlinear operator $G$ for each $\varphi=\left(\varphi_{1}, \varphi_{2}\right)$ $\in P A P\left(R, R^{2}, v\right), \quad(G \varphi):=x_{\varphi}(t)$ where

$x_{\varphi}(t)=\left(\int_{-\infty}^{t} e^{-\int_{t}^{s} a(u) d u} \gamma_{1}(t) d t,-\int_{t}^{+\infty} e^{-\int_{t}^{s} a(u) d u} \gamma_{2}(t) d t\right)$,

where

$$
\begin{aligned}
\gamma_{1}(t)= & \varphi_{2}(t)+\phi_{1}(t) \\
\gamma_{2}(t)=- & a^{2}(t) \varphi_{1}(t)-g\left(\varphi_{1}(t)\right)\left[\varphi_{2}(t)-a(t) \varphi_{1}(t)+\phi_{1}(t)\right] \\
& -h_{0}\left(\varphi_{1}(t)\right)-\sum_{i=1}^{n} h_{i}\left(\varphi_{1}\left(t-\sigma_{i}(t)\right)\right)+\phi_{2}(t) .
\end{aligned}
$$

Then $G \varphi \in P A P\left(R, R^{2}, v\right)$.

Proof . According to $\left(\mathrm{N}_{1}\right)-\left(\mathrm{N}_{4}\right)$, it is easily to see that $G \varphi \in B C\left(R, R^{2}\right)$ by using a similar argument in the proof of Lemma 2.1 in [18]. Let $\gamma_{1}(t)=\gamma_{11}(t)+\gamma_{12}(t)$, $\gamma_{2}(t)=\gamma_{21}(t)+\gamma_{22}(t)$ and

$$
\begin{aligned}
x_{\varphi}(t) & =\left(\int_{-\infty}^{t} e^{-\int_{t}^{s} a(u) d u} \gamma_{11}(t) d t,-\int_{t}^{+\infty} e^{-\int_{t}^{s} a(u) d u} \gamma_{12}(t) d t\right) \\
& +\left(\int_{-\infty}^{t} e^{-\int_{t}^{s} a(u) d u} \gamma_{21}(t) d t,-\int_{t}^{+\infty} e^{-\int_{t}^{s} a(u) d u} \gamma_{22}(t) d t\right) \\
& =Z_{\varphi}(t)+T_{\varphi}(t) .
\end{aligned}
$$

Since $M[a]>0$ from theory of exponential dichotomy in [4], we get that

$$
\int_{-\infty}^{t} e^{-\int_{t}^{s} a(u) d u} \gamma_{11}(t) d t,-\int_{t}^{+\infty} e^{-\int_{t}^{s} a(u) d u} \gamma_{12}(t) d t \in A P(R)
$$

is a solution of the following almost periodic differential equation

$$
y^{\prime}(t)=-a(t) y(t)+\gamma_{i 1}(t), \quad i=1,2 .
$$

Now we will show that $T_{\varphi}(t) \in P A P\left(R, R^{2}, v\right)$. From [17] we get

$$
\begin{aligned}
& 0 \leq \lim _{r \rightarrow \infty} \frac{1}{\mu(-r, r)} \int_{-r}^{r}\left(\int_{-\infty}^{t} e^{-\int_{s}^{t} a(u) d u}\left|T_{\varphi}(s)\right| d s\right) \nu(t) d t \\
& \leq K \lim _{r \rightarrow \infty} \frac{1}{\mu(-r, r)} \int_{-r}^{r}\left(\int_{-\infty}^{t} e^{-a(t-s)}\left|T_{\varphi}(s)\right| d s\right) \nu(t) d t \\
& \leq K \lim _{r \rightarrow \infty} \frac{1}{\mu(-r, r)} \int_{-r}^{r}\left(\int_{0}^{\infty} e^{-a(t-s)}\left|T_{\varphi}(s-u)\right| d s\right) \nu(t) d t=0
\end{aligned}
$$

Hence, $T_{\varphi}(t) \in P A P\left(R, R^{2}, v\right)$. It turns out that $G \varphi \in$

$\operatorname{PAP}\left(R, R^{2}, v\right)$

Theorem 3.2 Let $\left(\mathrm{N}_{1}\right)-\left(\mathrm{N}_{4}\right)$ hold and $v<1, \frac{\chi}{1-v}$ and $\pi<1$. Then there exists a unique weighted pseudo almost periodic solution of (1.2) in region

$$
U=\left\{\varphi \mid\left\|\varphi-\varphi_{0}\right\| \leq \frac{\chi v}{1-v}, \varphi \in P A P\left(\left(R, R^{2}, v\right)\right\},\right.
$$

where

$$
\varphi_{0}=\left(\int_{-\infty}^{t} e^{-\int_{t}^{s} a(u) d u} \phi_{1}(t) d t, \int_{t}^{+\infty} e^{-\int_{t}^{s} a(u) d u} \phi_{2}(t) d t\right) .
$$

Proof. We can see [4] that $U$ is closed subset. Define a mapping $\Delta: U \rightarrow U$, by setting

$$
(\Delta \phi)=\left(\begin{array}{c}
x_{\phi} \\
y_{\phi}
\end{array}\right)
$$

where,

$$
\begin{aligned}
& x_{\phi}=\int_{-\infty}^{t} e^{-\int_{t}^{s} a(u) d u}\left[\varphi_{2}(s)+\phi_{1}(s)\right] d s \\
& y_{\phi}(t)=-\int_{t}^{+\infty} e^{-\int_{t}^{s} a(u) d u} \\
& \times\left[\begin{array}{l}
-a^{2}(s) \varphi_{1}(s)-g\left(\varphi_{1}(s)\right)\left[\varphi_{2}(s)-a(s) \varphi_{1}(s)\right. \\
\left.+\phi_{1}(s)\right]-h_{0}\left(\varphi_{1}(s)\right)-\sum_{i=1}^{n} h_{i}\left(\varphi_{1}\left(s-\sigma_{i}(s)\right)\right)+\phi_{2}(t)
\end{array}\right] d s .
\end{aligned}
$$

It is clear that 


$$
\begin{aligned}
\left\|\varphi_{0}\right\| & \leq \sup _{t \in R} \max \left\{\begin{array}{l}
\int_{-\infty}^{t} e^{-\int_{t}^{s} a(u) d u} \phi_{1}(s) d s, \\
\int_{t}^{+\infty} e^{-\int_{t}^{s} a(u) d u} \phi_{2}(s) d s
\end{array}\right\} \\
& \leq \max \left\{\frac{\sup _{t \in R}\left|\phi_{1}(\mathrm{t})\right|}{a^{-}}, \frac{\sup _{t \in R}\left|\phi_{2}(\mathrm{t})\right|}{a^{-}}\right\}=\chi<1 .
\end{aligned}
$$

Also

$$
\|\varphi\|_{\infty} \leq\left\|\varphi-\varphi_{0}\right\|+\left\|\varphi_{0}\right\|_{\infty} \leq \frac{\chi v}{1-v}+\chi=\frac{\chi}{1-v}<1 .
$$

Therefore we can write

$$
\left\|\Delta \varphi-\varphi_{0}\right\|_{\infty}=\left(\begin{array}{l}
\left|\int_{-\infty}^{t} e^{-\int_{t}^{s} a(u) d u} \varphi_{2}(t) d t\right| \\
\left|\int_{t}^{+\infty} e^{-\int_{t}^{s} a(u) d u} \gamma_{2}^{s}(t) d t\right|
\end{array}\right),
$$

where

$$
\begin{aligned}
\gamma_{2}^{s}(t)= & -a^{2}(t) \varphi_{1}(t)-g\left(\varphi_{1}(t)\right) \\
& \times\left[\varphi_{2}(t)-a(t) \varphi_{1}(t)+\phi_{1}(t)\right] \\
& -h_{0}\left(\varphi_{1}(t)\right)-\sum_{i=1}^{n} h_{i}\left(\varphi_{1}\left(t-\sigma_{i}(t)\right)\right) .
\end{aligned}
$$

Then, from (1.5) we get

$$
\begin{aligned}
& \left\|\Delta \varphi-\varphi_{0}\right\|_{\infty}= \\
& \left(a^{-}\right)^{-1} \varlimsup_{t \rightarrow \infty} \max \left\{1, \sup _{t \in R}\left[\begin{array}{l}
a^{2}(t)+\xi[1+a(t) \\
+\phi_{1}(t)+\sum_{i=1}^{n} H_{i}
\end{array}\right]\right\}\|\varphi\|_{\infty} \\
& =v\|\varphi\|_{\infty} \leq v \frac{\chi}{1-v} .
\end{aligned}
$$

Also

$$
\begin{aligned}
& \|\Delta \varphi\|_{\infty} \leq\left\|\Delta \varphi-\varphi_{0}\right\|_{\infty}+\left\|\varphi_{0}\right\| \\
& \leq v \frac{\chi}{1-v}+\chi=\frac{\chi}{1-v}<1 . \\
& \|(\Delta \varphi)(t)-(\Delta \eta)(t)\|_{\infty}=\left(\begin{array}{l}
\left|\left(\Delta \varphi_{1}\right)(t)-\left(\Delta \eta_{1}\right)(t)\right| \\
\left|\left(\Delta \varphi_{1}\right)(t)-\left(\Delta \eta_{1}\right)(t)\right|
\end{array}\right) \\
& \leq\left(\begin{array}{l}
\int_{-\infty}^{t} e^{-\int_{t}^{s} a(u) d u}\left|\varphi_{2}(s)-\eta_{2}(s)\right| d s \\
\int_{t}^{+\infty} e^{-\int_{t}^{s} a(u) d u}\left|\gamma_{2}(t)-\tilde{\gamma}_{2}(t)\right| d t
\end{array}\right)
\end{aligned}
$$

$$
\begin{aligned}
& \leq\left(\begin{array}{l}
\int_{-\infty}^{t} e^{-\int_{t}^{s} a(u) d u} d s, \int_{t}^{+\infty} e^{-\int_{t}^{s} a(u) d u} d s \\
\times \sup _{t \in R}\left[a^{2}(t)+\xi\left[2+a(t)+\phi_{1}(t)+\sum_{i=0}^{n} H_{i}\right]\right.
\end{array}\right)^{T}\left\|\varphi_{2}-\eta_{2}\right\|_{\infty} \\
& \leq\left(a^{-}\right)^{-1} \max \left(1, \sup _{t \in R}\left[a^{2}(t)+\xi\left[2+a(t)+\phi_{1}(t)+\sum_{i=0}^{n} H_{i}\right]\right)\right. \\
& \times\left\|\varphi_{2}-\eta_{2}\right\|_{\infty}=\pi\left\|\varphi_{2}-\eta_{2}\right\|_{\infty} .
\end{aligned}
$$

From $N_{3}$, we can conclude that $\Delta$ is a contraction. It follows that $\Delta$ has a unique fixed point $q \in U$ of (1.5), $\Delta q=q$. From Lemma $3.1 \quad q$ is weighted pseudo almost periodic solution. The proof is complete.

\section{Example}

We consider following Liénard-type system of (1.2) with $a(t)=6+\cos t, \quad \phi_{1}(t)=-32+\sin t$, $\phi_{2}(t)=-33-\sin \sqrt{3} t-\cos \sqrt{5} t+e^{-t}, \sigma_{i}(t)=\frac{i}{2} \sin ^{2} t$, $g(x)=\arctan \left(x^{2}+1\right), h_{i}(x)=\frac{1}{2}(|x+1|-|x-1|), \sigma_{i}(t)=\frac{i}{4} \sin ^{2} t$, where $i=0,1,2$. Then $\quad a^{-}=5, \pi=\frac{1}{5}<1, \quad v=\frac{1}{5}<1$, $\chi=\frac{3}{4}<1, \quad H=\xi=1, \quad v(t)=e^{t}$. Then $\left(N_{1}\right)-\left(N_{4}\right)$ hold, thus system (1.2) has a unique weighted pseudo almost periodic solution.

\section{Conclusion}

In this study, some sufficient conditions were obtained for weighted pseudo almost periodic solutions of the system (1.2). When we look at [4], some results regarding pseudo almost periodic solutions for that system are obtained. For $t \geq 0$, under the weight $v(t)=e^{-t}$, the function $f(t)=\cos t+\cos \pi t+\arctan t$ is weighted pseudo almost periodic, but is not the usual pseudo almost periodic function. So the set of weighted pseudo almost periodic functions is general than the classical set of pseudo almost periodic functions. Thus, our results are new and more comprehensive than that in [4].

\section{References}

[1] A. M. Fink; Almost Periodic Differential Equations, vol. 377 of Lecture Notes in Mathematics, Springer, Berlin, Germany, 1974. 
[2] C. Zhang; Almost Periodic Type Functions and Ergodicity, Kluwer Academic/Science Press, Beijing, 2003.

[3] H. Gao, B. W. Liu; Almost periodic solution for a class of Lienard-type systems with multiple varying time delays, Applied Mathematical Modelling 34 (2010), 7279.

[4] Xu, Changjin; Liao, Maoxin Existence and uniqueness of pseudo almost periodic solutions for Liénard-type systems with delays. Electron. J. Differential Equations 2016, Paper No. 170, 8 pp.

[5] Xu, Y., Positive almost periodic solutions for a class of nonlinear Duffing equations with a deviating argument. Electron. J. Qual. Theory Differ. Equ., 49 (2012), 1-9.

[6] Peng, L.Q., Wang, W.T, Positive almost periodic solutions for a class of nonlinear Duffing equations with a deviating argument. Electron. J. Qual. Theory Differ. Equ., 49 (2010), 1-12.

[7] Liu, B., Tunc, C., Pseudo almost periodic solutions for a class of nonlinear Duffing system with a deviating argument. J. Appl. Math. Comput., 49 (2015), 233-242.
[8] Diagana, T., Existence of weighted pseudo almost periodic solutions to some non-autonomous differential equations. Int. J. Evol. Equ.,2 (2008),397-410.

[9] Diagana, T.,Weighted pseudo-almost periodic solutions to some differential equations. Non-linear Anal. 8 (2008), 2250-2260.

[10] M'hamdi, M. S, Aouiti, C., Touati,A.; Alimi, Adel M.; Snasel., Weighted pseudo almost-periodic solutions of shunting inhibitory cellular neural networks with mixed delays. Acta Math. Sci. Ser. B Engl. Ed., 36 (2016), 16621682.

[11] Zhao,L., Li, Y., Global exponential stability of weighted pseudo-almost periodic solutions of neutral type high-order Hopfield neural networks with distributed delays. Abstr. Appl. Anal., (2014), 17 pp.

[12] Xu, Y., Weighted pseudo-almost periodic delayed cellular neural networks. Neural Comput Appl, 28 (2017), 1-6.

[13] Liu, Bingwen Almost periodic solutions for a class of Liénard-type systems with continuously distributed delays. Math. Comput. Modelling 46 (2007), no. 5-6, 595-603. 